\title{
Numerical investigation on low calorific syngas combustion in the opposed-piston engine
}

\begin{abstract}
The aim of this study was to investigate a possibility of using gaseous fuels of a low calorific value as a fuel for internal combustion engines. Such fuels can come from organic matter decomposition (biogas), oil production (flare gas) or gasification of materials containing carbon (syngas). The utilization of syngas in the barrel type Opposed-Piston (OP) engine arrangement is of particular interest for the authors. A robust design, high mechanical efficiency and relatively easy incorporation of Variable Compression Ratio (VCR) makes the OP engine an ideal candidate for running on a low calorific fuel of various compostion. Furthermore, the possibility of online compression ratio adjustment allows for engine the operation in Controlled Auto-Ignition (CAI) mode for high efficiency and low emission. In order to investigate engine operation on low calorific gaseous fuel authors performed $3 D$ CFD numerical simulations of scavenging and combustion processes in the 2-stroke barrel type Opposed-Piston engine with use of the AVL Fire solver. Firstly, engine operation on natural gas with ignition from diesel pilot was analysed as a reference. Then, combustion of syngas in two different modes was investigated - with ignition from diesel pilot and with Controlled Auto-Ignition. Final engine operating points were specified and corresponding emissions were calculated and compared. Results suggest that engine operation on syngas might be limited due to misfire of diesel pilot or excessive heat releas which might lead to knock. A solution proposed by authors for syngas is CAI combustion which can be controlled with application of VCR and with adjustment of air excess ratio. Based on preformed simulations it was shown that low calorific syngas can be used as a fuel for power generation in the Opposed-Piston engine which is currently under development at Warsaw University of Technology.
\end{abstract}

Key words: opposed-piston, syngas, combustion, CAI, CFD

\section{Introduction}

The development of the industrial sector became the reason of the emissions growth. In order to counterbalance the harmful effect of pollutants on the environment, emission regulations are becoming more and more strict. This trend forces engine manufacturers to constantly improve their devices and develop new solutions that will help to meet new emission standards. In recent years research in clean internal combustion (IC) engine technology is focused on renewable energy sources such as natural gas and alternative gaseous fuels. Such fuels can come from organic matter decomposition (biogas), oil production (flare gas) or gasification of materials containing carbon (syngas). Additionally, when fuel is considered as a waste it needs to be utilized due to environmental regulations what raises additional costs. Under present conditions, economic factors provide the strongest argument for the use of syngas as fuel [1].

In areas where the price of petroleum fuels is high, or where supplies are unreliable, syngas can provide an economically viable solution. Syngas consists of about $40 \%$ combustible gases, mainly carbon monoxide (CO), hydrogen $\left(\mathrm{H}_{2}\right)$ and methane $\left(\mathrm{CH}_{4}\right)$. The remainder is made up of non-combustible gases, primarily nitrogen $\left(\mathrm{N}_{2}\right)$ and carbon dioxide $\left(\mathrm{CO}_{2}\right)$. The presence of $\mathrm{H}_{2}$ in gaseous fuel increases flame propagation speed and widen flammability limits extending the lean limit of gas operation without entering the lean misfire region. With the lean mixture combustion higher thermal efficiency and low $\mathrm{NO}_{\mathrm{x}}$ emission are possible to attain [2]. Despite advantages of utilizing syngas as a fuel in internal combustion engines, there are still several challenges problems that researchers are trying to overcome. One of the biggest problems is varying composition of syngas depending on the source of the fuel. Since main components of the syngas have considerably different combustion properties, the overall behaviour of the fuel can be significantly changed with change of the $\mathrm{CH}_{4} / \mathrm{H}_{2} / \mathrm{CO}$ proportions. Furthermore, with increasing of the $\mathrm{H}_{2}$ fraction in the fuel, the minimum energy required for ignition is reduced leading to increased probability of mixture auto-ignition in the region of end gas in the combustion chamber.

There are several works dedicated to investigation of syngas utilization in IC engines. Some of them consider spark-ignition (SI) combustion system [3-5]. However, under high load conditions, SI is not suitable for this kind of fuel due to the fluctuation of the syngas composition which makes it difficult to obtain stable combustion. In order to achieve reliable ignition and low cycle-to-cycle variations it is beneficial to utilize syngas in IC engine that operate in dual-fuel mode under compression ignition with a lean mixture, using a pilot injection of diesel fuel. Firstly, a pilot diesel fuel is injected, resulting in ignition and a subsequent temperature rise in the combustion chamber. Then, the primary gaseous fuel (syngas) is ignited due to temperature increase in the chamber with subsequent combustion.

Dual-fuel engines powered by syngas have been widely studied by several research groups. Tomita et al. [6] studied the combustion characteristics in a supercharged dual-fuel engine with syngas as primary fuel and ignition from micro-pilot. They stated that a premixed flame of syngas-air mixture develops from multiple flame kernels produced by the ignition of diesel pilot. It was also determined that a certain increase in the hydrogen content of the syngas allows the engine to operate even at equivalence ratios as low as $\Phi=0.45$ with stable combustion and high efficiency. 
In a series of papers Roy et al. [7-9] performed experimental studies of performance and characteristics of supercharged dual-fuel engine fuelled by producer gases with varying hydrogen content and by hydrogen-rich coke oven gas. In their work, authors also studied the effect of fuel injection parameters on engine performance and emissions. They detected characteristic two-stage heat release during the combustion of syngas at a pilot fuel injection pressure of $40 \mathrm{MPa}$ and $10^{\circ}$ before top dead centre (BTDC). With further advance of pilot injection more than $13.5^{\circ}$ BTDC knocking combustion occurred. When the injection pressure was increased to $80 \mathrm{MPa}$, two-stage heat release combustion was observed at $9^{\circ}$ BTDC, and knock occurred after $11^{\circ}$ BTDC. Moreover, authors also studied the effect of hydrogen content in the fuel and the effect of exhaust gas recirculation (EGR) on the performance and exhaust emissions of a dual-fuel engine. They found that the engine power obtained from syngas with high $\mathrm{H}_{2}$ content was $12 \%$ greater than that obtained from syngas with low $\mathrm{H}_{2}$ content. They also showed that high $\mathrm{H}_{2}$ content is superior to low $\mathrm{H}_{2}$ content for leaner syngas operation.

Azimov et al. [10-12] performed experimental and numerical investigation of ignition, combustion and exhaust emission characteristics of Micro-Piloti-Ignited (MPI) dualfuel (DF) engine fuelled with natural gas, syngas and hydrogen. Authors also reported characteristic two-stage heat release profile. The first stage is gaseous fuel flame propagation and the second is end-gas mixture auto-ignition. The second stage can be mainly controlled by the pilot fuel injection timing, gaseous fuel equivalence ratio, and EGR rate. Authors named this combustion mode as PREMIER (PREmixed Mixture Ignition in the End-gas Region) and stated that an increase in the fuel mass fraction burned in the second stage of heat release affects the rate of maximum pressure rise. Furthermore, increase in hydrogen content in syngas induces an increase in the mean combustion temperature, IMEP and efficiency, but also a significant increase in $\mathrm{NO}_{\mathrm{x}}$ emissions.

The most recent concept is to run IC engine fuelled with syngas in Homogeneous Charge Compression Ignition (HCCI)/Controlled Auto-Ignition (CAI) combustion mode for high thermal efficiency and low emissions. It is a unique form of combustion based on charge auto-ignition at desired crank angle. It has been demonstrated that HCCI gasoline engine can achieve fuel economy levels comparable to those of a Compression Ignition (CI) engines, while producing engine-out $\mathrm{NO}_{\mathrm{x}}$ emissions that are as low as tailpipe $\mathrm{NO}_{\mathrm{x}}$ emissions from a conventional SI engine equipped with a three-way catalyst [13].

Although the idea of HCCI/CAI combustion is desirable, it is also very challenging to implement in an IC engine due to absence of direct ignition timing control (i.e. spark). In order to guarantee correct combustion timing, closedloop combustion control is necessary. This type of control is supposed to vicariously influence the ignition timing via different measures (i.e. VCR). Additionally, in case of utilizing syngas as a fuel in HCCI engine it would be possible to become independent from diesel fuel conventionally used for ignition, since ignition in HCCI is controlled only by in-cylinder conditions. Although there have been many studies on HCCI combustion of gasoline, HCCI of syngas is still not well investigated. It is probably due to the fact, that varying composition of syngas might be very challenging for adopting HCCI combustion. Nevertheless, in one of the recent studies Bhaduri et al. [14] performed experimental study of running IC engine fuelled with impure syngas in HCCI mode. Authors proved stability of their concept with 24-hour test. However, relatively low IMEP (2.5 bar) and high $\mathrm{NO}_{\mathrm{x}}$ emission (150 ppm) were achieved. The conclusion was that the concept requires further improvement to make commercially viable.

The aim of the current work is to investigate a possibility of utilizing low calorific syngas as a fuel in the barrel type Opposed-Piston engine which is currently under development at Warsaw University of Technology. The engine is equipped with diesel pilot injection for direct ignition timing control, as well as with an online VCR and water injection systems for indirect ignition timing control. The goal is to achieve high performance and low emissions in order to make the engine commercially viable. Such a complex combustion control system is challenging to implement in the real engine. Therefore, numerical simulations can become a useful tool for better understanding of the combustion process and can shorten the time span for engine development. In this study 3D CFD numerical simulations of the scavenging, injection and combustion processes were performed. With numerical simulation it was possible to determine engine operating points in dual-fuel mode with diesel pilot ignition and in CAI mode.

\section{Opposed-Piston engines}

There are several types of OP engine configurations (cranckless, single crankshaft, multiple crankshaft, rotary or barrel) [15]. The barrel type OP engine is of particular interest for the authors because of its robust design, high mechanical efficiency and relatively easy incorporation of a Variable Compression Ratio. In the barrel type OP engine cylinders' axes are parallel to the drive shaft axis. Linear to rotary motion is changed through the special plate with connecting rods mounted on ball bearings. An 8-cylinder barrel type OP piston engine concept is presented in Fig. 1.

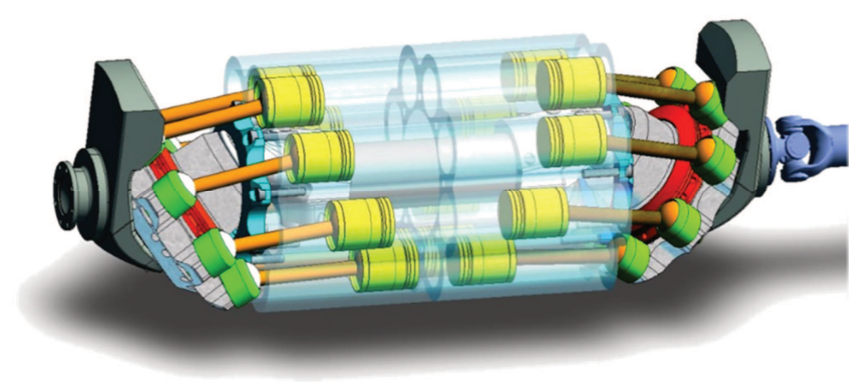

Fig. 1. An 8-cylinder barrel-type OP engine concept

The possibility of achieving high thermal efficiency brings Opposed-Piston (OP) engines back into interest of research centres. An advantage of such design is that combustion chamber is formed between moving pistons. The main thermal benefits arise from the geometrical shape of the combustion chamber. The ratio of the area to the volume of the combustion chamber $\mathrm{A} / \mathrm{V}$ in the $\mathrm{OP}$ engine is 
twice lower than in conventional IC engines [15] resulting in low heat losses and increased thermal efficiency. In the OP engine designed as a 2-stroke the poppet valves become redundant and with adapting a uniflow scavenging, the volumetric, trapping and scavenging efficiency become comparable with a 4-stroke. Because of the lack of the cylinder head, a scavenging process need to be handled differently than in a conventional 4-stroke engine. In the OP engine usually intake and exhaust ports in the cylinder liner are responsible for the scavenging. When pistons reach their Bottom Dead Centre (BDC), ports are opened and charge is exchanged due to pressure difference between the intake and exhaust manifolds.

Several studies have been dedicated to investigation of thermal benefits of OP engine configuration. For example in [16] authors performed detailed thermodynamic analysis to demonstrate the fundamental efficiency advantage of a 2stroke OP engine over a standard 4-stroke engine. They found that the 4-stroke OP have increased indicated thermal efficiency compared to the 4-storke conventional engine. Furthermore, the 2-stroke OP engine additionally benefitted from doubled firing frequency, which allowed for leaner operating conditions and reduced energy release densities resulting in shorter combustion durations without exceeding maximum rate of pressure rise constraints. When evaluated over a representative engine speed/load operating map, the 2-stroke OP engine achieved 10.4\% lower specific fuel consumption than the 4-stroke OP engine.

\section{Syngas combustion modelling}

In order to properly predict ignition and combustion processes in dual-fuel engine running on syngas it is necessary to account for diesel pilot spray, variable composition of the fuel, charge stratification or wall interaction, what leads to multi-dimensional CFD modelling with detailed kinetic schemes for fuel oxidation. Furthermore, modelling ignition process from diesel pilot requires to use kinetic scheme which incorporates chemical reactions for $\mathrm{CH}_{4} / \mathrm{CO} / \mathrm{H}_{2}$ as well as for diesel surrogate, n-heptane (n$\mathrm{C}_{7} \mathrm{H}_{16}$ ). Although, this kind of mechanisms are available, they usually have too many species to be directly used for 3D CFD numerical simulations of IC engine. For example POLIMI_TOT kinetic mechanism [17] comprises 484 species and 19341 reactions, while mechanism that can be used 3D CFD engine simulations should be the size of less than 100 species and 500 reactions in order to provide reasonable computation times.

During recent years several kinetic schemes for oxidation of $\mathrm{CH}_{4} / \mathrm{CO} / \mathrm{H}_{2}$ mixtures that could be used for 3D CFD modelling of syngas combustion have been developed. Some of them are GRImech-3.0 [18], USC Mech 2.0 [19], POLIMI_C1C3 [20] or Sandiego [21]. However, as already mentioned, they are not suitable for dual-fuel engine simulations due to lack of $n-\mathrm{C}_{7} \mathrm{H}_{16}$ oxidation chemistry. In order to overcome this problem, Azimov et al. [12] developed their own mechanism for multidimensional CFD simulation of syngas combustion in a micro-pilot-ignited dual-fuel engine. They combined simple mechanisms for $\mathrm{CH}_{4}$, $\mathrm{H}_{2} / \mathrm{CO}$ and $\mathrm{H}_{2} / \mathrm{CO} / \mathrm{O}_{2}$ oxidation and included a single-step reaction chemistry of $n-C_{7} H_{16}$. The mechanism was validated by using a chemical kinetics code and a multidimension- al CFD code, and the results were compared with experimental data of combustion in a supercharged dual-fuel engine. The mechanism predicted the engine performance well, including the cylinder pressure history, heat-release rate data with respect to syngas composition equivalence ratio, and injection timing.

\section{Construction and validation of syngas/n-heptane kinetic mechanism}

In current work authors decided that the best way to model syngas combustion in pilot-ignited dual-fuel engine is to combine GRImech-3.0 [18], which is well known and validated kinetic scheme for $\mathrm{CH}_{4} / \mathrm{CO} / \mathrm{H}_{2}$ oxidation, with chemistry of $n-\mathrm{C}_{7} \mathrm{H}_{16}$. However, instead of using only single reaction chemistry like in [12], a simple and validated scheme for $\mathrm{n}-\mathrm{C}_{7} \mathrm{H}_{16}$ oxidation from Wisconsin ERC [22] was combined with GRImech-3.0. Any duplicate reactions were eliminated from $n-C_{7} \mathrm{H}_{16}$ scheme resulting in final mechanism comprising 61 species and 347 reactions. The new mechanism ERC-GRI was validated against experimental data of ignition delay times (IDT) of methane/air [23] and n-heptane/air [24] mixtures, as well as against experimental data of laminar burning velocity (LBV) of methane/air [25] and n-heptane/air [26] mixtures. Ignition delay time simulations were performed in a constant volume reactor with adaptive time step in Cantera 2.3.0. in Matlab R2016b environment. Laminar burning velocities were calculated in Cantera 2.3.0. in Python 3.6. environment using free flame model and automatic refinement of a grid. Results of validation are given in Fig. 2, Fig. 3, Fig. 4 and Fig. 5.

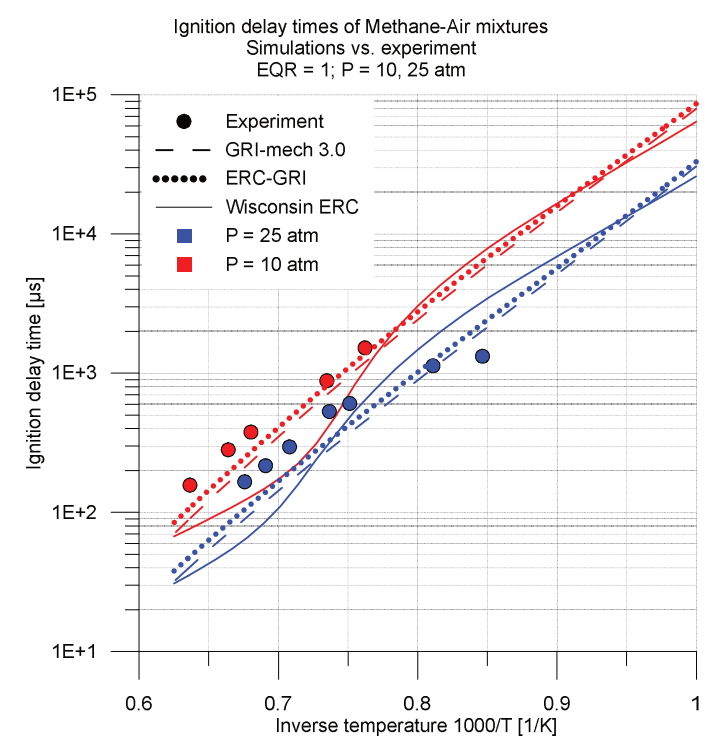

Fig. 2. Validation of IDTs for methane/air mixtures

Results of validation show that Wisconsin ERC mechanism was able to predict IDTs of n-heptane/air mixtures with reasonable agreement. On the other hand, it predicted LBVs to be twice as high as experimental values for nheptane/air mixtures. Interestingly, combination of mechanisms in a single ERC-GRI mechanism resulted in an improvement of both IDTs and LBVs agreement for nheptane/air mixtures. Furthermore, the ability of correct 
prediction of IDTs and LBVs for methane/air mixtures from GRImech was remained. Overall, results suggest that new mechanism shows reasonable agreement with experimental IDTs and LBVs and can be used for multidimensional CFD simulations in a dual-fuel engine.

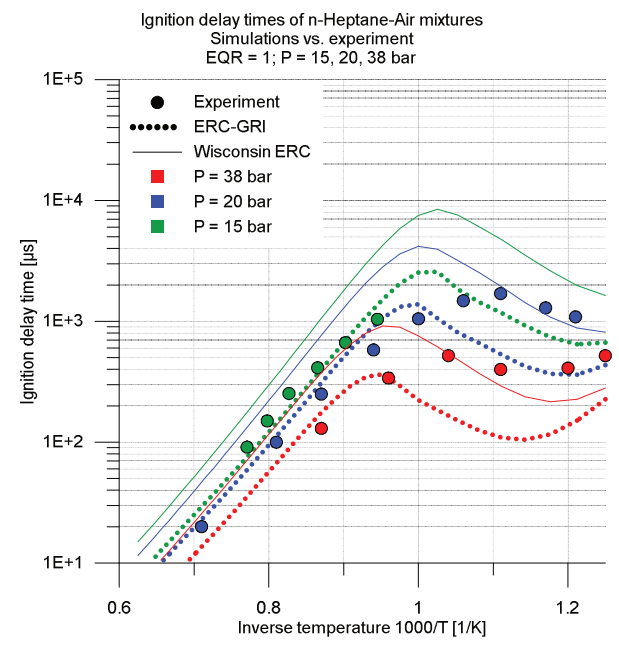

Fig. 3. Validation of IDTs for n-heptane/air mixtures

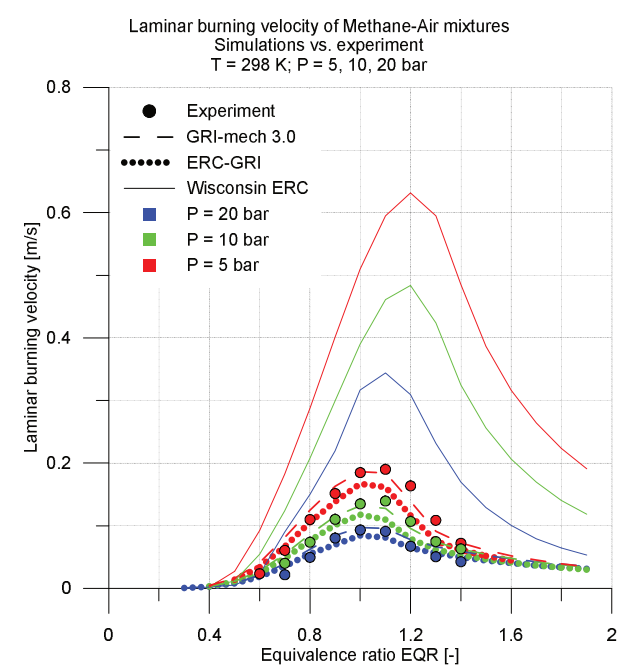

Fig. 4. Validation of LBVs for methane/air mixtures

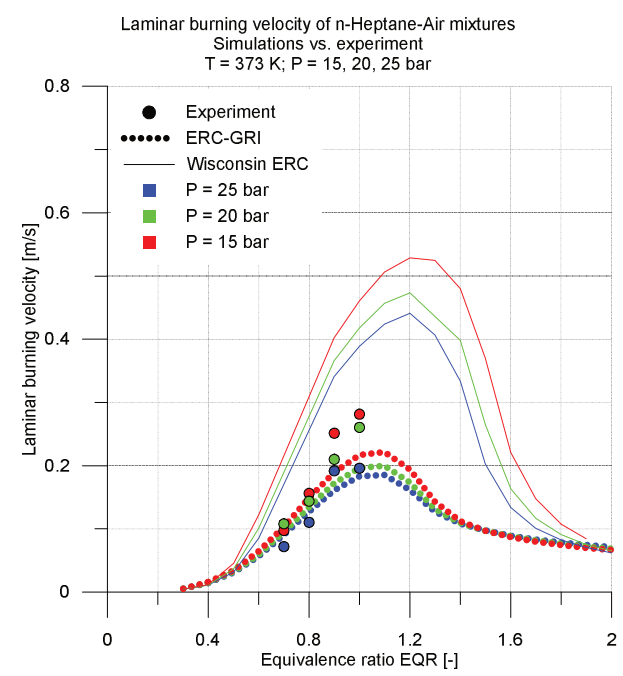

Fig. 5. Validation of LBVs for n-heptane/air mixtures

\section{Engine setup}

The engine considered in this study is a 2-cylinder, 2stroke, barrel-type OP engine with cylinders' axes parallel to the shaft axis. It is a research engine being currently developed at Warsaw University of Technology. The engine is mainly developed for power generation application with utilization of low calorific syngas as a fuel. However, the construction of the engine allows for operation on different kind of fuels with different ignition modes. Namely, it is possible to run the engine in SI mode, micro-pilotignition mode or CAI mode. The basic engine parameters are given in Table 1.

Table 1. Engine parameters

\begin{tabular}{|c|c|}
\hline Engine type & $\begin{array}{c}\text { 2-stroke } \\
\text { Opposed-Piston } \\
\text { Turbocharged }\end{array}$ \\
\hline Number of cylinders & 2 \\
\hline Bore & $0.055 \mathrm{~m}$ \\
\hline Stroke & $0.2 \mathrm{~m}$ \\
\hline Engine speed & $1500 \mathrm{rpm}$ \\
\hline Compression ratio & VCR $8 \div 18$ \\
\hline Fuel & Syngas \\
& Natural gas \\
Gasoline \\
Diesel
\end{tabular}

Although it is possible to utilize different fuels in the engine, this study is focused on syngas combustion simulations. A composition of the syngas considered in this work is given in Table 2. One can notice significant amount of inert gases in the fuel. Hence, the Lower Heating Value of the fuel is only $4.74 \mathrm{MJ} / \mathrm{kg}$. Additionally, engine operation on pure methane was modelled in order to have a comparison between low calorific syngas and methane which is well known and investigated fuel.

Table 2. Syngas composition

\begin{tabular}{|c|c|c|}
\hline Species & Mass fraction & Mole fraction \\
\hline $\mathrm{CH}_{4}$ & 0.02640 & 0.04586 \\
\hline $\mathrm{H}_{2}$ & 0.00519 & 0.07175 \\
\hline $\mathrm{CO}_{2}$ & 0.24403 & 0.15453 \\
\hline $\mathrm{H}_{2} \mathrm{O}$ & 0.01289 & 0.01994 \\
\hline $\mathrm{CO}$ & 0.17435 & 0.17346 \\
\hline $\mathrm{C}_{2} \mathrm{H}_{2}$ & 0.00186 & 0.00199 \\
\hline $\mathrm{C}_{2} \mathrm{H}_{4}$ & 0.02007 & 0.01994 \\
\hline $\mathrm{N}_{2}$ & 0.51521 & 0.51254 \\
\hline
\end{tabular}

The biggest challenge associated with syngas combustion is its variable composition which can influence the ignition and combustion processes. In order to assure reliable ignition, diesel-pilot is utilized for initiation of combustion. As for the combustion process itself, the engine runs with VCR which can be adjusted according to current load and fuel composition. The goal is to work always with the 
highest possible compression ratio for high efficiency and on the same time avoid knock, which is related to the excessive heat release rate.

In case of CAI operation, which is also possible with the OP engine, additional issue of the ignition timing control has to be taken into account. A proposed solution is closedloop control based on VCR. However, application of CAI for syngas with variable composition still can be very challenging. Hence, the investigated engine is equipped with the following solutions that will allow CAI combustion control:

- Variable Compression Ratio for indirect ignition timing control,

- Variable Port Timing for scavenging and EGR control,

- Direct fuel injection for fuel stratification and limiting the heat release rate,

- Manifold Water Injection for indirect ignition timing control and limiting knock,

- Direct Water Injection for ignition control through direct internal EGR cooling,

- Turbocharging for increased engines IMEP and wider operation area.

\section{Simulations setup}

\subsection{Operating conditions in simulations}

Numerical simulations of combustion in this study were performed using the AVL Fire 3D CFD solver based on Finite Volume Method (FVM) discretization. For turbulence modelling, the $k-\zeta-f$ turbulence model was used [27]. For hydrocarbon oxidation, the kinetic scheme described in section 4. was used. Simulations were performed for two types of ignition - Micro-Pilot-Ignition and CAI. In case of MPI both $\mathrm{CH}_{4}$ and syngas fuels were considered. As for CAI, only cases with syngas were calculated in order to define possible operating points of the engine running on this fuel. Summary of operating conditions considered in simulations is given in Table 3. It includes three different boost pressures $\mathrm{P}_{\mathrm{b}}$ and corresponding intake temperatures as well as equivalence ratios, compression ratios and energy fraction of the pilot which were defined in simulations.

Table 3. Operating conditions

\begin{tabular}{|c|c|}
\hline \multirow{2}{*}{ Boost pressure $\mathrm{P}_{\mathrm{b}}$} & $\begin{array}{l}3.0 \mathrm{bar} \text { (absolute) } \\
2.5 \text { bar (absolute) } \\
2.0 \text { bar (absolute) }\end{array}$ \\
\hline \multirow{2}{*}{ Intake temperature } & $\begin{array}{l}410 \mathrm{~K} \text { (at 3.0 bar) } \\
390 \mathrm{~K} \text { (at } 2.5 \text { bar) } \\
365 \mathrm{~K} \text { (at 2.0 bar) }\end{array}$ \\
\hline \multirow{2}{*}{ Equivalence ratio } & 0.5 \\
& 1.0 \\
\hline Compression Ratio & $8-14$ \\
\hline \multirow{2}{*}{ Fuel in simulations } & Syngas \\
\hline Ignition & Methane \\
\hline Pilot energy fraction & CAI \\
\hline EGR mass fraction & $5.0-10.0 \%$ \\
\hline
\end{tabular}

\subsection{Numerical mesh and boundary conditions}

Before setting up simulations, numerical mesh was prepared for one cylinder and half of the intake and exhaust manifolds. Two types of meshes were defined - steady mesh for intake/exhaust manifolds and moving mesh for cylinder volume. Movement of the cylinder mesh was handled by changing positions of the nodes representing intake-side and exhaust-side pistons separately according to the given piston displacement curves. Simultaneously, positions of the nodes between pistons were interpolated every time step according to the pistons displacement. Meshes of the cylinder and intake/exhaust manifolds were connected with Arbitrary Interface at the contact of the cylinder wall and intake/exhaust ports. Total number of mesh elements for the entire model was of 1200 000, while mesh for the cylinder itself consisted of 200000 elements. The mesh of the cylinder used for simulations together with applied temperature boundary conditions is presented in Fig. 6. In this study temperature boundary condition was assumed to be dependent on the load, which is related to the boost pressure. Different temperatures were assumed on the intake-side and exhaust-side pistons. On the cylinder wall a temperature profile was defined. Summary of temperature boundary conditions is given in Table 4 .

Table 4. Temperature at boundary walls

\begin{tabular}{|c|c|c|c|}
\hline & $\begin{array}{c}\text { Intake-side } \\
\text { piston } \mathrm{T}_{\text {in }}\end{array}$ & $\begin{array}{c}\text { Exhaust-side } \\
\text { piston } \mathrm{T}_{\mathrm{ex}}\end{array}$ & $\begin{array}{c}\text { Cylinder wall } \\
\mathrm{T}_{\text {cyl }}\end{array}$ \\
\hline $\mathrm{P}_{\mathrm{b}}=2.0 \mathrm{bar}$ & $550 \mathrm{~K}$ & $605 \mathrm{~K}$ & $400-550 \mathrm{~K}$ \\
\hline $\mathrm{P}_{\mathrm{b}}=2.5 \mathrm{bar}$ & $600 \mathrm{~K}$ & $660 \mathrm{~K}$ & $400-600 \mathrm{~K}$ \\
\hline $\mathrm{P}_{\mathrm{b}}=3.0 \mathrm{bar}$ & $650 \mathrm{~K}$ & $715 \mathrm{~K}$ & $400-650 \mathrm{~K}$ \\
\hline
\end{tabular}
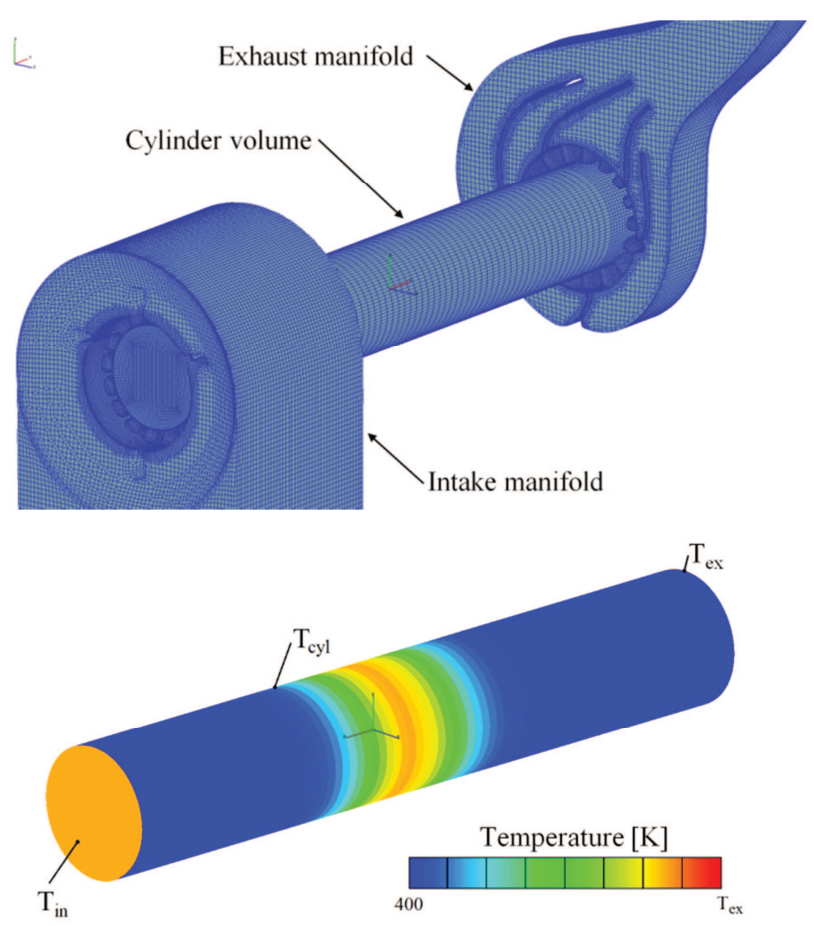

Fig. 6. Numerical mesh and temperature boundary conditions

\subsection{Operation targets and summary of cases}

Simulations were performed for different compression ratios, equivalence ratios and different amounts of directly or indirectly injected water. For each case two engine cycles were calculated. For the first cycle approximate initial conditions in the cylinder before the scavenging were assumed. At the end of the first cycle realistic conditions in 
the cylinder were obtained for the second cycle scavenging and combustion. Only results from the second cycle are presented and compared in this study.

In order to compare the results and draw conclusion specific targets for the combustion results need to be assumed. In this study following parameters are considered:

- Crank angle of 50\% accumulated heat release (CA50) was considered as a measure of combustion timing. Target for CA50 in this study was $5.0^{\circ} \mathrm{CA}$ ATDC;

- Maximum pressure rise $\mathrm{dP} / \mathrm{dCA}$ was assumed as the limiting parameter for the knock, since the knock itself was not modelled in this work. Target for maximum $\mathrm{dP} / \mathrm{dCA}$ was of $10 \mathrm{bar} / \mathrm{CA}$;

- Delay between start of pilot injection and crank angle of $5 \%$ accumulated heat release (CA5D). Although no target was defined for CA5D time, it helped to compare delay of the primary fuel ignition between cases.

For each type of ignition (MPI or CAI) different procedures for combustion timing control were adopted. In case of MPI injection timing of the pilot was adjusted in order to meet the CA50 target, while for CAI adjustment of compression ratio was performed for each calculated case to match the CA50 target.

A combination of two different fuels, different compression ratios, different equivalence ratios, different boost pressures and different ignition/combustion modes resulted in a number of calculated cases, which are summarized in Table 5. The case naming follows the pattern XCR000ER00P00, where X stands for fuel (M for methane and $\mathrm{S}$ for syngas), CR000 is compression ratio with one decimal place, ER00 is equivalence ratio with one decimal place and P00 is boost pressure with one decimal place.

Table 5. Summary of investigated cases

\begin{tabular}{|c|c|c|c|}
\hline & $\mathrm{P}_{\mathrm{b}}=2.0 \mathrm{bar}$ & $\mathrm{P}_{\mathrm{b}}=2.5 \mathrm{bar}$ & $\mathrm{P}_{\mathrm{b}}=3.0 \mathrm{bar}$ \\
\hline $\begin{array}{c}\text { METHANE } \\
\text { MPI }\end{array}$ & $\begin{array}{l}\text { MCR110ER10P20 } \\
\text { MCR120ER10P20 } \\
\text { MCR130ER10P20 } \\
\text { MCR130ER05P20 }\end{array}$ & $\begin{array}{l}\text { MCR090ER10P25 } \\
\text { MCR100ER10P25 } \\
\text { MCR110ER10P25 } \\
\text { MCR100ER05P25 }\end{array}$ & $\begin{array}{l}\text { MCR080ER10P30 } \\
\text { MCR090ER10P30 } \\
\text { MCR080ER05P30 }\end{array}$ \\
\hline $\begin{array}{c}\text { SYNGAS } \\
\text { MPI }\end{array}$ & $\begin{array}{l}\text { SCR110ER10P20 } \\
\text { SCR120ER10P20 } \\
\text { SCR130ER10P20 } \\
\text { SCR130ER05P20 }\end{array}$ & $\begin{array}{l}\text { SCR090ER10P25 } \\
\text { SCR100ER10P25 } \\
\text { SCR110ER10P25 } \\
\text { SCR100ER05P25 } \\
\end{array}$ & $\begin{array}{l}\text { SCR080ER10P30 } \\
\text { SCR090ER10P30 } \\
\text { SCR080ER05P30 }\end{array}$ \\
\hline $\begin{array}{l}\text { SYNGAS } \\
\text { CAI }\end{array}$ & SCR140ER05P20 & SCR112ER05P25 & SCR092ER05P30 \\
\hline
\end{tabular}

\section{Results and discussion}

\subsection{Scavenging results}

Presentation of the results should start with results of the scavenging process. During the scavenging in a 2-stroke engine the exhaust gases are removed from the combustion chamber which is filled with the fresh charge at the same time. During this process it is important to remove as much of combustion products from the previous cycle as possible and not to let fuel reach the exhaust. If any fuel reaches the exhaust it is considered as HC emission. Investigated engine is equipped with specially designed intake and exhaust systems which allow for charge stratification and minimize fuel mass lost to the exhaust. Results of the scavenging process for boost pressure of $\mathrm{P}_{\mathrm{b}}=3.0 \mathrm{bar}$ and compression ratio $\mathrm{CR}=9.0$ are given in Fig. 7 . It can be noticed that temperature stratification of the charge is related to the
EGR, which was left in the chamber after the scavenging. Although noticeable amount of exhaust gases concentration is visible close to the exhaust-side piston, the overall EGR mass fraction in the engine can be reduced up to $5 \%$. The advantage of the incorporated intake/exhaust system can be seen on the plots of equivalence ratio in Fig. 7. Generally combustion chamber is divided in 4 zones. Starting from the left side (intake-side) the zones are air/fuel/air/exhaust. Thanks to this separation it was possible to reduce fuel lost to exhaust and increase charge stratification. Highly stratified charge is supposed to limit excessive heat release and allow engine operation at increased compression ratios for high efficiency.

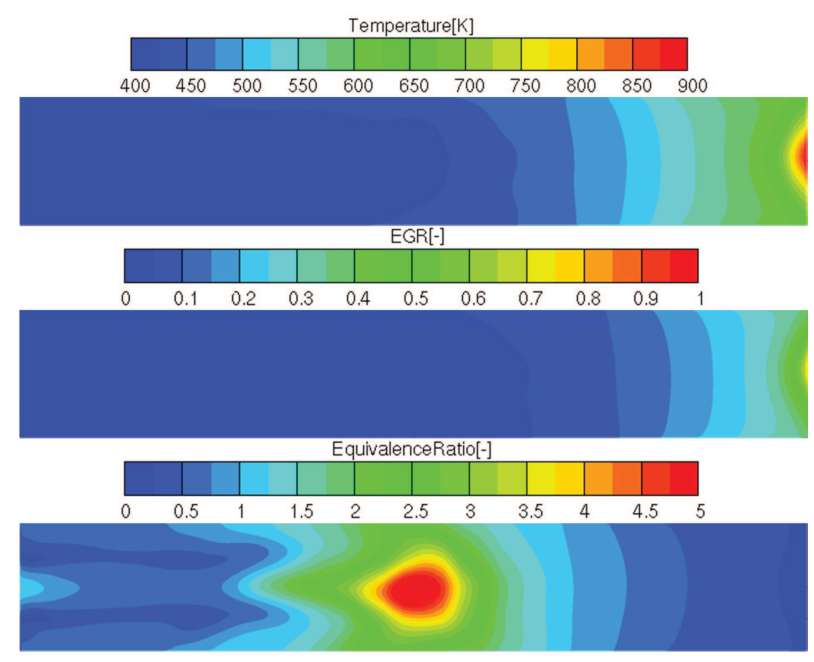

Fig. 7. Results of temperature, EGR fraction and equivalence ratio in cross-section along the cylinder

\subsection{Combustion with $\phi=1.0$ and MPI mode}

The determination of the possible operation points of the OP engine running in dual-fuel mode started with simulations of stoichiometric mixtures. Calculations were performed for both methane and syngas to have a comparison between these fuels. The goal was to meet CA50 timing and work with the highest possible compression ratio at which pressure rise $\mathrm{dP} / \mathrm{dCA}$ will not exceed $10.0 \mathrm{bar} / \mathrm{CAD}$. The CA5D time was also monitored in order to know how given conditions influence the delay time between start of pilot injection and ignition of the primary fuel. The injected mass of the pilot was adjusted for each case to contain $5 \%$ of the total energy released in one cycle. Results of calculated cases are given in Table 6. Cases which fulfilled both defined targets are marked with green color. For methane it should be possible to work with $\mathrm{P}_{\mathrm{b}}=3.0$ bar and $\mathrm{CR}=8.0$, $\mathrm{P}_{\mathrm{b}}=2.5$ bar and $\mathrm{CR}=9.0, \mathrm{P}_{\mathrm{b}}=2.0$ bar and $\mathrm{CR}=11.0$. The lower were intake pressure and temperature, the higher compression ratio could be set. For syngas it was not possible to determine suitable operating points.

The main problem was to adjust CA50 timing. It was mainly because of the delay time CA5D which normally was much longer than in corresponding cases with methane. The reason for this behavior was probably composition of the combustible mixture. For syngas, significant fraction of the inert gases $\left(\mathrm{N}_{2}, \mathrm{CO}_{2}, \mathrm{H}_{2} \mathrm{O}\right)$ in the fuel resulted low $\mathrm{O}_{2}$ mass fraction in the final mixture, which was of $\sim 12.8 \%$ in 
all cases, while for methane $\mathrm{O}_{2}$ mass fraction in the mixture was of $\sim 20.6 \%$ in all cases. This difference resulted in longer delay of pilot ignition and difficulties in controlling combustion timing. On the other hand, one can notice that in some cases CA5D delay time was shorter for syngas than for methane (e.g. case CR080ER10P30). It was caused by autoignition of the mixture before or during the pilot injection, which also did not allow to control timing of combustion. Finally, when conditions in the chamber allowed to obtain correct CA50 timing, they caused excessive heat release rate and maximum pressure rise $\mathrm{dP} / \mathrm{dCA}$ beyond the specified limit.

Table 6. Cases calculated with $\phi=1.0$ and MPI mode

\begin{tabular}{|c|c|c|c|c|c|c|c|}
\hline Case & \begin{tabular}{|c|}
$\mathrm{P}_{\mathrm{b}}$ \\
{$[\mathrm{bar}]$} \\
\end{tabular} & $\begin{array}{l}\mathrm{CR} \\
{[-]}\end{array}$ & $\begin{array}{l}\text { Pilot } \\
{[\mathrm{CA}]} \\
\end{array}$ & $\begin{array}{l}\text { Pilot } \\
{[\mathrm{mg}]}\end{array}$ & $\begin{array}{l}\text { CA5D } \\
{[\mathrm{CAD}]} \\
\end{array}$ & \begin{tabular}{|l} 
CA50 \\
{$[\mathrm{CA}]$} \\
\end{tabular} & $\begin{array}{c}\mathrm{dP} / \mathrm{dCA} \\
{[\mathrm{b} / \mathrm{CaD} / \mathrm{CAD}]}\end{array}$ \\
\hline MCR080ER10P30 & \multirow{4}{*}{3.0} & \multirow{2}{*}{8.0} & -13.2 & 5.0 & 12.0 & 5.2 & 9.48 \\
\hline SCR080ER10P30 & & & -13.2 & 3.7 & 22.7 & 16.5 & 7.6 \\
\hline MCR090ER10P30 & & \multirow{2}{*}{9.0} & -9.2 & 5.0 & 8.6 & 5.1 & 15.27 \\
\hline SCR090ER10P30 & & & -6.6 & 3.7 & 4.6 & 3.1 & 13.8 \\
\hline MCR090ER10P25 & \multirow{6}{*}{2.5} & \multirow{2}{*}{9.0} & -14.6 & 4.5 & 13.1 & 4.9 & 9.14 \\
\hline SCR090ER10P25 & & & $\mid-14.6$ & 3.3 & 35.8 & 37.8 & 0.86 \\
\hline MCR100ER10P25 & & \multirow{2}{*}{10.0} & -10.2 & 4.5 & 9.3 & 5.0 & 11.72 \\
\hline SCR100ER10P25 & & & -14.6 & 3.3 & 15.0 & 5.2 & 16.9 \\
\hline MCR110ER10P25 & & \multirow{2}{*}{11.0} & -8.0 & 4.5 & 7.4 & 5.0 & 17.28 \\
\hline SCR110ER10P25 & & & -7.0 & 3.3 & 7.2 & 3.6 & 22.77 \\
\hline MCR110ER10P20 & \multirow{6}{*}{2.0} & \multirow{2}{*}{11.0} & -13.2 & 3.8 & 11.8 & 4.8 & 9.58 \\
\hline SCR110ER10P20 & & & $\mid-13.2$ & 2.8 & 34.2 & 38.3 & 0.99 \\
\hline MCR120ER10P20 & & \multirow{2}{*}{12.0} & -9.8 & 3.8 & 9.0 & 5.1 & 11.51 \\
\hline SCR120ER10P20 & & & -15.2 & 2.8 & 15.7 & 5.4 & 20.6 \\
\hline MCR130ER10P20 & & \multirow{2}{*}{13.0} & -8.2 & 3.8 & 7.5 & 4.9 & 15.8 \\
\hline SCR130ER10P20 & & & -9.0 & 2.8 & 9.8 & 4.8 & 24.12 \\
\hline
\end{tabular}

\subsection{Combustion with $\phi=0.5$ and MPI mode}

Due to problems with combustion control of stoichiometric syngas mixture it was decided to calculate cases with equivalence ratio reduced to $\phi=0.5$. Only cases for which it was possible to determine operating points in previous section were recalculated. Mass of the diesel-pilot remained the same and now it contains $\sim 10.0 \%$ of the total energy released in the cycle for methane fuel and $\sim 8.0 \%$ of the total energy released in the cycle for syngas fuel. Results are given in Table 7, plots of pressure trace and ROHR are given in Fig. 8 and Fig. 9, visualization of ignition and combustion processes is shown in Fig. 10 and Fig. 11. Reduction of equivalence ratio resulted in increase of the $\mathrm{O}_{2}$ mass fraction in the methane mixture to $\sim 21.2 \%$ and in the syngas mixture to $\sim 16.6 \%$. This increase is supposed to shorten ignition delay of diesel-pilot and improve ignition process of the syngas. Eventually, it was possible to meet CA50 and $\mathrm{dP} / \mathrm{dCA}$ targets for all recalculated cases. Although CA5D times were still longer for syngas mixture, it was possible to control combustion timing for reduced equivalence ratios.

It is interesting to compare pressure trace and ROHR between calculated cases. In Fig. 8 and Fig. 9 one can notice characteristic profile of the heat release which was also reported by other researchers in [7-12]. Heat release is divided in two stages. The first stage is ignition of the diesel-pilot followed by the flame propagation of the primary fuel. The second stage is auto-ignition of the end gas, that results in the secondary peak of the heat release. Generally, heat release profile is similar in considered cases for methane and syngas combustion. However, some differences can be noticed. For methane the primary peak of heat release is higher which is caused by faster combustion of the diesel-pilot, as well as larger dose of the pilot. For syngas the secondary peak of heat release is higher, what suggests that syngas is more prone to auto-ignition.

Table 7. Cases calculated with $\phi=0.5$ and MPI mode

\begin{tabular}{|c|c|c|c|c|c|c|c|}
\hline Case & $\begin{array}{c}\mathrm{P}_{\mathrm{b}} \\
{[\mathrm{bar}]}\end{array}$ & $\begin{array}{c}\text { CR } \\
{[-]}\end{array}$ & $\begin{array}{c}\text { iilot } \\
{[\mathrm{CA}]}\end{array}$ & $\begin{array}{c}\text { Pilot } \\
{[\mathrm{mg}]}\end{array}$ & $\begin{array}{c}\text { CA5D } \\
{[\mathrm{CAD}]}\end{array}$ & $\begin{array}{c}\text { CA50 } \\
{[\mathrm{CA}]}\end{array}$ & $\begin{array}{c}\text { dP/dCA } \\
{[\mathrm{bar} / \mathrm{CAD}]}\end{array}$ \\
\hline MCR080ER05P30 & 3.0 & 8.0 & -14.0 & 5.0 & 8.3 & 5.1 & 7.6 \\
\hline SCR080ER05P30 & 3.0 & 8.0 & -16.7 & 3.7 & 16.2 & 4.8 & 6.7 \\
\hline MCR110ER05P25 & 2.5 & 11.0 & -12.2 & 4.5 & 6.9 & 4.9 & 8.2 \\
\hline SCR110ER05P25 & 2.5 & 11.0 & -11.2 & 3.3 & 8.6 & 5.0 & 6.1 \\
\hline MCR130ER05P20 & 2.0 & 13.0 & -11.2 & 3.8 & 5.8 & 4.8 & 9.3 \\
\hline SCR130ER05P20 & 2.0 & 13.0 & -8.2 & 2.8 & 6.6 & 4.9 & 9.0 \\
\hline
\end{tabular}

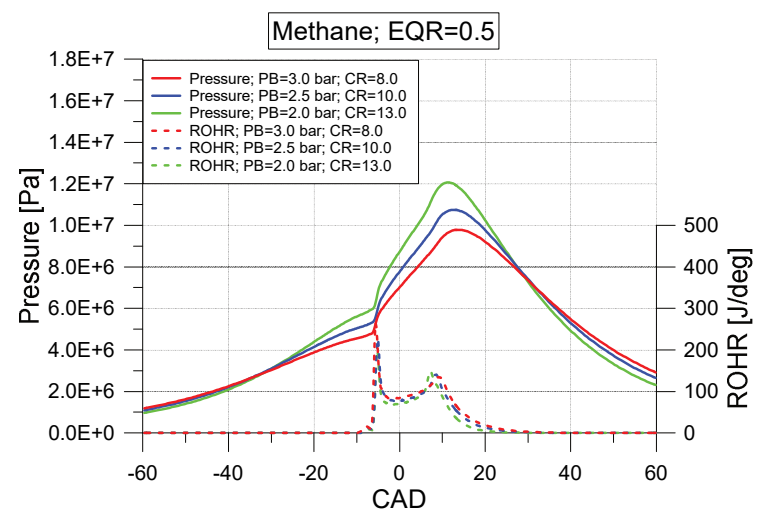

Fig. 8. Pressure trace and ROHR for methane and MPI mode

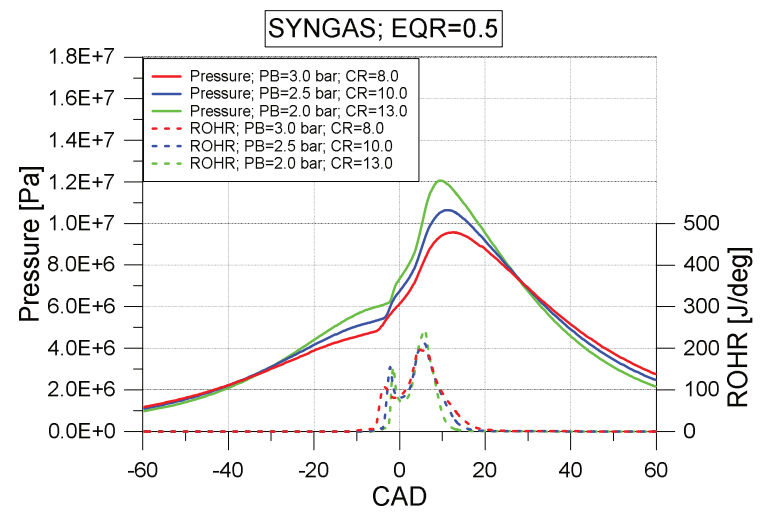

Fig. 9. Pressure trace and ROHR for syngas and MPI mode

Similar observation can be made based on ignition and combustion visualization presented in Fig. 10 and Fig. 11. In these figures 3D results of spray, temperature in a plane along the cylinder and flame surface are shown. Surface that represents the flame is an iso-surface of the temperature of $1200 \mathrm{~K}$. In case of syngas longer delay between start 
of pilot injection and ignition of the primary fuel can be distinguished as well as slower flame propagation in early stage of combustion process. Also auto-ignition of the end gas is more clear for syngas than for methane. End gas always ignites at the exhaust-side piston, in the region of high temperature EGR which was left from previous cycle.

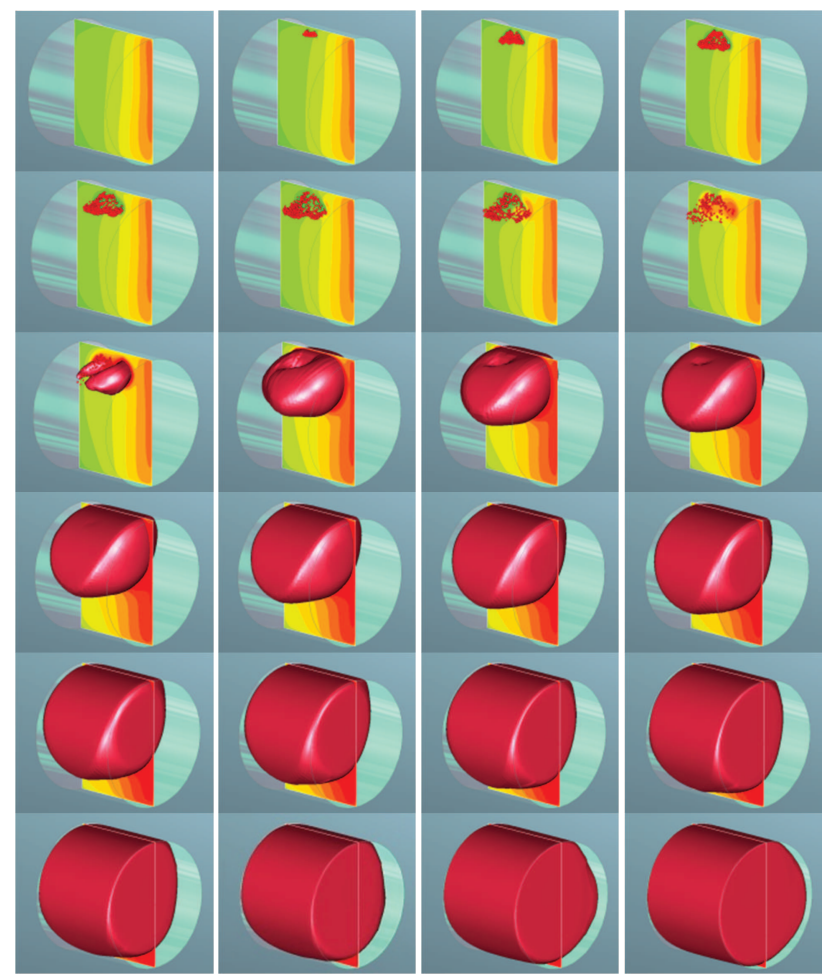

Fig. 10. Visualisation of ignition and combustion for case MCR080ER05P30 (methane MPI)

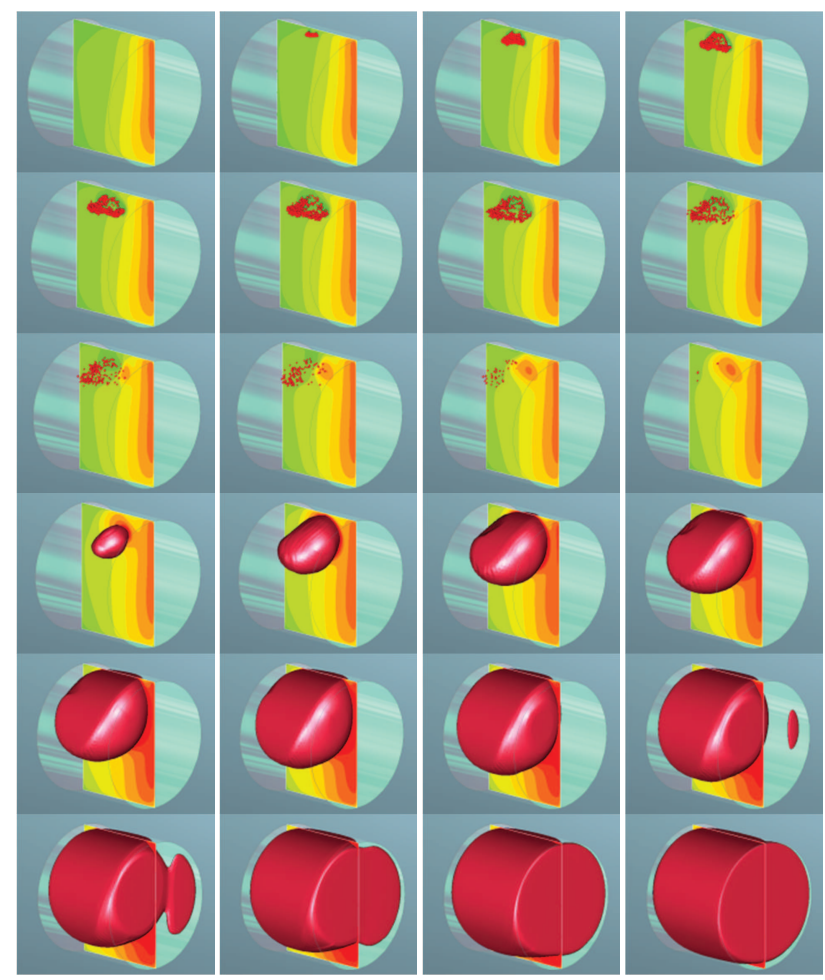

Fig. 11. Visualisation of ignition and combustion for case SCR080ER05P30 (syngas MPI)

\subsection{Combustion with $\phi=0.5$ and CAI mode}

The last calculated set of cases considered syngas combustion in CAI mode. The benefits arising from engine running in CAI mode are: independence on diesel fuel (no pilot), increased efficiency and low emissions. The procedure for simulations was to start with cases calculated with MPI mode and equivalence ratio of $\phi=0.5$, remove injection of diesel pilot and adjust compression ratio in order to meet the CA50 target. Based on results given in Table 8 it should be possible to run the engine in CAI mode with $\mathrm{P}_{\mathrm{b}}=$ 3.0 bar and $\mathrm{CR}=9.2, \mathrm{P}_{\mathrm{b}}=2.5$ bar and $\mathrm{CR}=11.2, \mathrm{P}_{\mathrm{b}}=2.0$ bar and CR $=14.0$. Only for case SCR140ER05P20 pressure rise limit was exceed. However, it was still very close to $10.0 \mathrm{bar} / \mathrm{CA}$ and it should be possible to reach this limit with further adjustment of equivalence ratio.

Table 8. Cases calculated with $\phi=0.5$ and CAI mode

\begin{tabular}{|c|c|c|c|c|}
\hline Case & $\begin{array}{c}\mathrm{P}_{\mathrm{b}} \\
{[\mathrm{bar}]}\end{array}$ & $\begin{array}{c}\mathrm{CR} \\
{[-]}\end{array}$ & $\begin{array}{c}\text { CA50 } \\
{[\mathrm{CA}]}\end{array}$ & $\begin{array}{c}\mathrm{dP} / \mathrm{dCA} \\
{[\mathrm{bar} / \mathrm{CAD}]}\end{array}$ \\
\hline SCR092ER05P30 & 3.0 & 9.2 & 5.5 & 5.2 \\
\hline SCR112ER05P25 & 2.5 & 11.2 & 4.6 & 7.3 \\
\hline SCR140ER05P20 & 2.0 & 14.0 & 5.3 & 11.8 \\
\hline
\end{tabular}

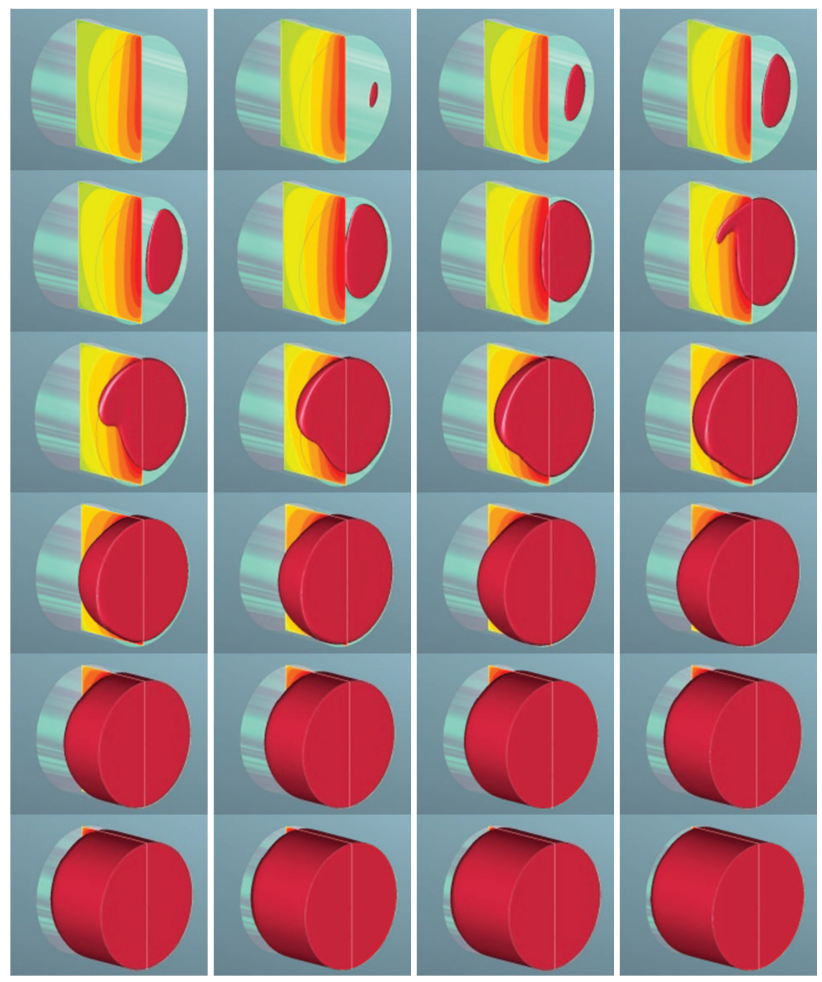

Fig. 12. Pressure trace and ROHR for syngas and CAI mode

Results of pressure trace, ROHR and visualization of CAI combustion are given in Fig. 12 and Fig. 13. It is interesting to see difference between CAI combustion mode and MPI dual-fuel mode. In case CAI mode mixture always ignites at the exhaust-side piston in a region of high temperature EGR. Then flame propagates from the exhaustside piston to the intake-side piston through stratified mixture. Because there is no secondary auto-ignition, there is also no secondary peak in the heat release. 


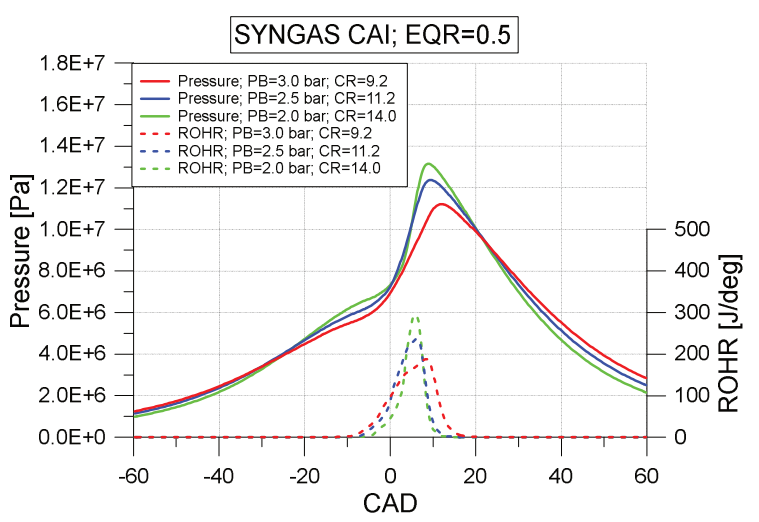

Fig. 13.Visualisation of ignition and combustion for case SCR092ER05P30 (syngas CAI)

\subsection{Performance and emissions}

This section contains comparison between possible operating points in terms of performance and emissions. Results are also referred to EU regulations on pollutant emission in Non-Road Mobile Machinery [28]. Investigated engine fits in NRE-v/c-5 category of Stage V standards, for which $\mathrm{CO}$ emission limit is of $5.0 \mathrm{~g} / \mathrm{kWh}, \mathrm{HC}$ emission limit is of $0.19 \mathrm{~g} / \mathrm{kWh}$ and $\mathrm{NO}_{\mathrm{x}}$ emission limit is of $0.4 \mathrm{~g} / \mathrm{kWh}$. Results of IMEP, Indicated power, Thermal efficiency and emission of $\mathrm{CO}, \mathrm{HC}$ and $\mathrm{NO}_{\mathrm{x}}$ are given in Fig. 14-Fig. 19. When it comes to results of IMEP and power, it is clear that reduction of equivalence ratio for methane caused significant decrease in performance. For equivalence ratio $\phi=0.5$ and MPI combustion there is visible difference between methane and syngas, which comes from low LHV of syngas. Performance results for syngas combustion in MPI and CAI modes are comparable.

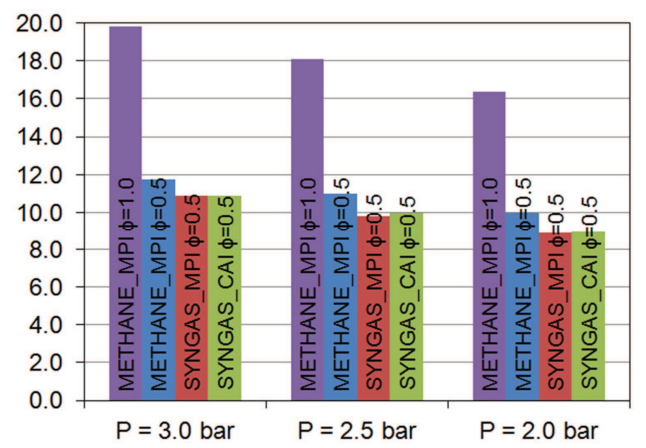

Fig. 14. Results of IMEP for final operating points

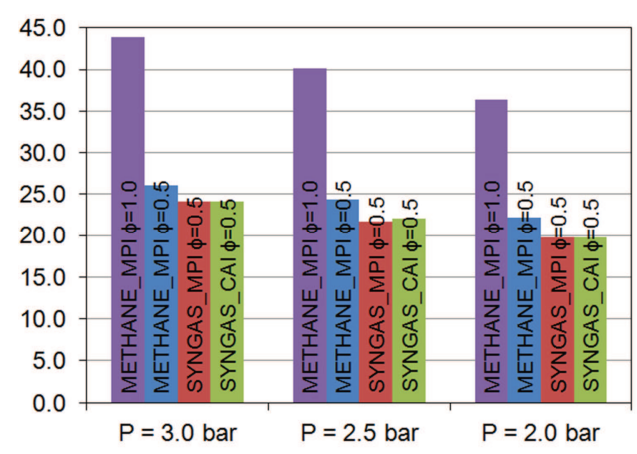

Fig. 15. Results of power for final operating points
In case of thermal efficiency again differences between equivalence ratio $\phi=1.0$ and $\phi=0.5$ for methane can be noticed. It can be related to the fact that for the lowered equivalence ratio, temperatures in the combustion chamber were also reduced. With reduced temperatures heat loses were lower and thermal efficiency increased. Furthermore, thermal efficiency generally increased with compression ratio and the highest obtained efficiency was of $47.8 \%$ for case MCR130ER05P20.

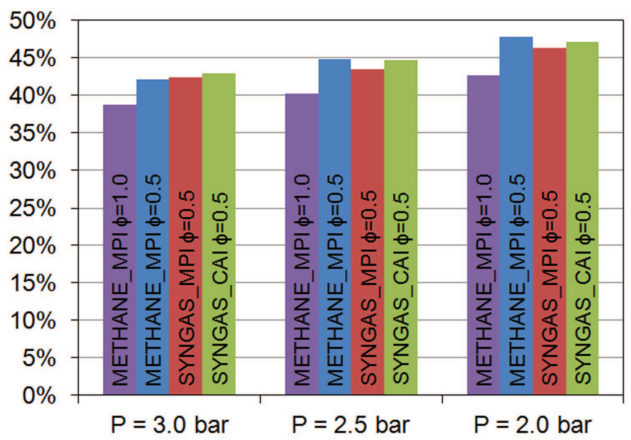

Fig. 16. Results of thermal efficiency for final operating points

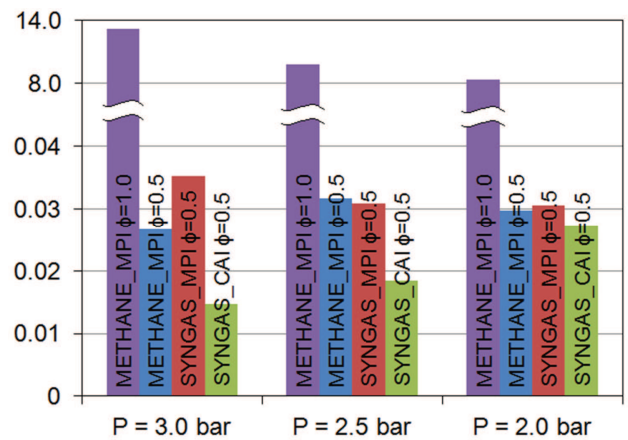

Fig. 17. Results of $\mathrm{CO}$ emission for final operating points

$\mathrm{CO}$ emission was the highest for cases with equivalence ratio of $\phi=1.0$. Change of equivalence ratio for methane to $\phi=0.5$ resulted in drastic reduction of $\mathrm{CO}$ emission. Then comparable results were obtained for methane and syngas with MPI mode. The lowest $\mathrm{CO}$ emission was obtained for syngas combustion in CAI mode and was much lower than EU regulations limit.

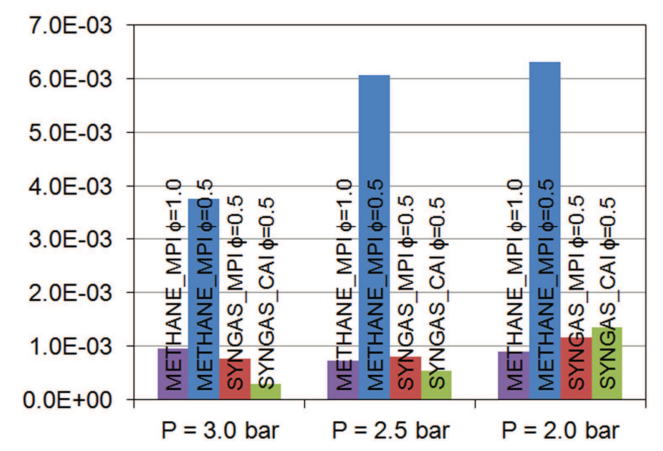

Fig. 18. Results of $\mathrm{HC}$ emission for final operating points

$\mathrm{HC}$ emission was very low in all investigated cases. The reason for this result is probably simplified geometry, which did not include piston ring pack and other crevice. In 
real engine some parts of the charge are forced into narrow regions during the compression stroke and returned to the combustion chamber during the expansion stroke to be expelled with the exhaust gases and contribute to HC emission.

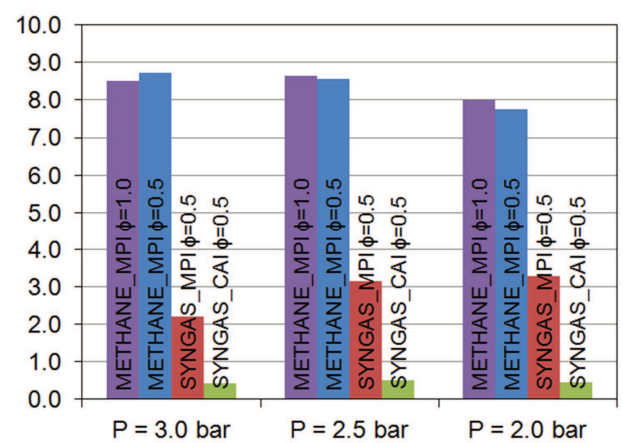

Fig. 19. Results of $\mathrm{NO}_{\mathrm{x}}$ emission for final operating points

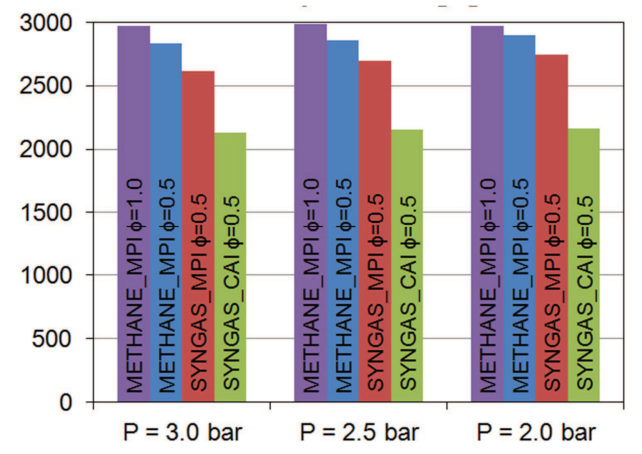

Fig. 20. Maximum temperatures in the combustion chamber

The last presented result is $\mathrm{NO}_{\mathrm{x}}$ emission. For methane combustion very similar $\mathrm{NO}_{\mathrm{x}}$ emission was obtained for equivalence ratio $\phi=1.0$ and $\phi=0.5$. Although maximum temperatures in the combustion chamber and $\mathrm{NO}_{\mathrm{x}}$ mass were reduced with lower equivalence ratio, the power output was also reduced and final $\mathrm{NO}_{\mathrm{x}}$ emission in $\mathrm{g} / \mathrm{kWh}$ was not improved. $\mathrm{NO}_{\mathrm{x}}$ emission for syngas with MPI mode was over $50 \%$ lower than for methane, which can be related to lower maximum temperatures in the combustion chamber in case of syngas. The lowest maximum temperatures in the combustion chamber were obtained for syngas combustion with CAI mode, what contributed to very low final
$\mathrm{NO}_{\mathrm{x}}$ emission, comparable to EU regulation limits of $0.4 \mathrm{~g} / \mathrm{kWh}$.

\section{Conclusions}

In this work multidimensional CFD combustion simulations for the 2-stroke, 2-cylinder barrel-type OpposedPiston engine were performed. Engine operation in dualfuel mode with MPI was considered for methane or syngas utilized as a primary fuel. Additionally, engine operation on syngas in CAI mode was analyzed. The following conclusions can be drawn:

- It should be possible to operate the engine on methane with stoichiometric mixtures and ignition from dieselpilot;

- Significant content of inert gases in syngas and low oxygen mass fraction in the final stoichiometric mixture resulted in long ignition delays of diesel-pilot and problems with combustion timing control in some of investigated cases. In cases where it was possible to control the combustion timing, auto-ignition of end gas and excessive heat release occurred. Finally, it was not possible to establish suitable operating point for engine running on stoichiometric mixtures of syngas;

- Reduction of equivalence ratio to $\phi=0.5$ allowed for engine operation in dual-fuel mode for both methane and syngas with ignition from diesel-pilot. The drawback was decrease in performance, but advantage was reduction of $\mathrm{CO}$ emission and increase in efficiency;

- The lowest emissions were obtained for engine operation on syngas in CAI mode with reduced equivalence ratios. Very low $\mathrm{NO}_{\mathrm{x}}$ emission were obtained due to limited maximum temperatures in the combustion chamber. Final engine-out emissions in CAI mode were within limits of current EU regulations.

\section{Acknowledgements}

This work is a part of Applied Research Programme of the National Centre for Research and Development within the scope of applied research in industry branches (programme path B) „Badania wysokosprawnego silnika wykorzystującego technologię HCCI do zastosowań w energetyce rozproszonej" (GENEKO).

The Fire calculation code was used as per the AVL AST University Partnership Program.

\section{Nomenclature}

ATDC after top dead center

BTDC before top dead center

CA crank angle

CA50 crank angle of 50\% accumulated heat

CA5D delay of $5 \%$ accumulated heat

CAD crank angle degrees

CAI controlled auto ignition

CI compression ignition

CFD computational fluid dynamics

CR compression ratio

DF dual fuel

EGR exhaust gas recirculation
HCCI homogeneous charge compression ignition

IDT ignition delay time

IC internal combustion

IMEP indicated mean effective pressure

LBV laminar burning velocity

LHV lower heating value

LPG liquified petrolum gas

MPI micro pilot ignition

OP opposed piston

ROHR rate of heat release

SI spark ignition

VCR variable compression ratio 


\section{Bibliography}

[1] LIEUWEN, T., YANG, V., YETTER, R. Synthesis gas combustion: fundamentals and applications. Taylor \& Francis Group; 2010.

[2] BADE SHRESTHA, S.O., KARIM, G.A. Hydrogen as an additive to methane for spark ignition engine applications. International Journal of Hydrogen Energy. 24(6), 577-586.

[3] PUSHP, M., MANDE, S. Development of $100 \%$ producer gas engine and field testing with pid governor mechanism for variable load operation. SAE Technical Paper. 2008, 2008-28-0035.

[4] YAMASAKI, Y., TOMATSU, G., NAGATA, Y., KANEKO, S. Development of a small size gas engine system with biomass gas (combustion characteristics of the wood chip pyrolysis gas). SAE Technical Paper. 2007, 2007-01-3612.

[5] ANDO, Y., YOSHIKAWA, K., BECK, M., ENDO, H. Research and development of a low-BTU gas-driven engine for waste gasification and power generation. Energy. 30(1112), 2206-2218.

[6] TOMITA, E., FUKATANI, N., KAWAHARA, N. et al. Combustion characteristics and performance of supercharged pyrolysis gas engine with micro-pilot ignition. $\mathrm{CI}$ MAC congress. 2007. Paper No. 178.

[7] ROY, M.M., TOMITA, E., KAWAHARA, N. et al. Effect of fuel injection parameters on engine performance and emissions of a supercharged producer gas-diesel dual fuel engine. SAE Technical Paper. 2009, 2009-01-1848.

[8] ROY, M.M., TOMITA E., KAWAHARA N. et al. Performance and emission comparison of a supercharged dual-fuel engine fueled by producer gases with varying hydrogen content. International Journal of Hydrogen Energy. 2009.

[9] ROY, M.M., TOMITA, E., KAWAHARA N. et al. Performance and emissions of a supercharged dual-fuel engine fueled by hydrogen-rich coke oven gas. International Journal of Hydrogen Energy. 2009.

[10] AZIMOV, U., TOMITA, E., KAWAHARA, N. Ignition, Combustion and exhaust emission characteristics of micropilot ignited dual-fuel engine operated under PREMIER combustion mode. SAE Technical Paper. 2011, 2011-01-1764.

[11] AZIMOV U., TOMITA E., KAWAHARA N., HARADA Y. Effect of syngas composition on combustion and exhaust emission characteristics in a pilot-ignited dual-fuel engine operated in PREMIER combustion mode. International Journal of Hydrogen Energy. 2011, 36, 11985-11996.

[12] AZIMOV, U., OKUNO, M., TSUBOI, K. et al. Multidimensional CFD simulation of syngas combustion in a micropilot-ignited dual-fuel engine using a constructed chemical kinetics mechanism. International Journal of Hydrogen Energy. 2011, 36, 13793-13807.

[13] ZHAO, H. HCCI and CAI engines for the automotive industry. Woodhead Publishing. 2007.

Rafał Pyszczek, MSc. - Faculty of Power and Aeronautical Engineering at Warsaw University of Technology.

e-mail:Rafal.Pyszczek@itc.pw.edu.pl

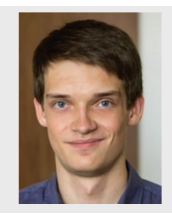

Paweł Mazuro, DEng. - Faculty of Power and Aeronautical Engineering at Warsaw University of Technology.

e-mail: Pawel.Mazuro@itc.pw.edu.pl
[14] BHADURI, S., BERGER, B., POCHET, M. et al. HCCI engine operated with unscrubbed biomass syngas. Fuel Processing Technology. 2017, 157, 52-58.

[15] FLINT M. Opposed Piston Engines: Evolution, Use, and Future Applications. Warrendale: SAE International. 2010

[16] HEROLD, R.E., WAHL, M.H., REGNER, G. et al. Thermodynamic benefits of opposed-piston two stroke engines. SAE Technical Paper. 2011, 2011-01-2216.

[17] RANZI, E., FRASSOLDATI, A., GRANA, R. et al. Hierarchical and comparative kinetic modeling of laminar flame speeds of hydrocarbon and oxygenated fuels. Progress in Energy and Combustion Science. 2012, 38(4), 468-501.

[18] SMITH, G.P., GOLDEN, D.M., FRENKLACH, M. et al. "GRI-Mech 3.0."

[19] WANG, H., YOU, X., JOSHI, A.V. et al. USC Mech Version II. High-Temperature Combustion Reaction Model of $\mathrm{H} 2 / \mathrm{CO} / \mathrm{C} 1-\mathrm{C} 4$ Compounds.

[20] RANZI, E., FRASSOLDATI, A., GRANA, R. et al. Hierarchical and comparative kinetic modeling of laminar flame speeds of hydrocarbon and oxygenated fuels. Progress in Energy and Combustion Science. 2012, 38(4), 468-501.

[21] Mechanical and Aerospace Engineering (Combustion Research) - University of California at San Diego, "Chemical-Kinetic Mechanisms for Combustion Applications, San Diego Mechanism web page."

[22] PATEL, A., KONG, S., REITZ, R. Development and validation of a reduced reaction mechanism for HCCI engine simulations. SAE Technical Paper. 2004, 2004-01-0558.

[23] BURKE, U., SOMERS, K.P., O'TOOLE, P. et al. An ignition delay and kinetic modeling study of methane, dimethyl ether, and their mixtures at high pressures. Combustion and Flame. 2015, 162(2) 315-330.

[24] ZHANG, K., BANYON, C., BUGLER, J., et al. An updated experimental and kinetic modeling study of n-heptane oxidation. Combustion and Flame. 2016, 172, 116-135.

[25] ROZENCHAN, G., ZHU, D.L., LAW, C.K., TSE, S.D. Outward propagation, burning velocities, and chemical effects of methane flames up to 60 ATM. Proceedings of the Combustion Institute. 2002, 29(2), 1461-1470.

[26] JERZEMBECK, S., PETERS, N., PEPIOT-DESJARDINS, P., PITSCH, H. Laminar burning velocities at high pressure for primary reference fuels and gasoline: Experimental and numerical investigation. Combustion and Flame. 2009, 156(2), 292-301.

[27] HANJAliĆ, K., POPOVAC, M., HADZIABDiĆ, M. A robust near-wall elliptic-relaxation eddy-viscosity turbulence model for CFD. International Journal of Heat and Fluid Flow. 2004, 25(6), 1047-1051.

[28] Regulation (EU) 2016/1628 of the European Parliament and of the Council of 14 September 2016 on requirements relating to gaseous and particulate pollutant emission limits and type-approval for internal combustion engines for non-road mobile machinery.

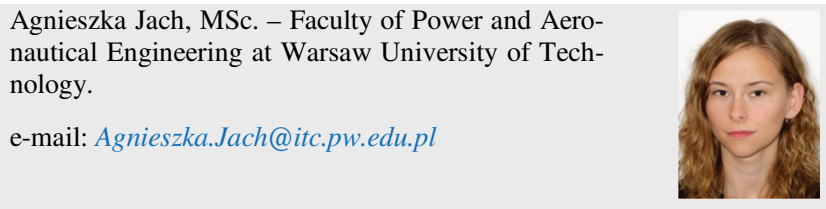

Prof. Teodorczyk Andrzej DSc., DEng.- Faculty of Power and Aeronautical Engineering at Warsaw University of Technology.

e-mail: Andrzej.Teodorczyk@itc.pw.edu.pl
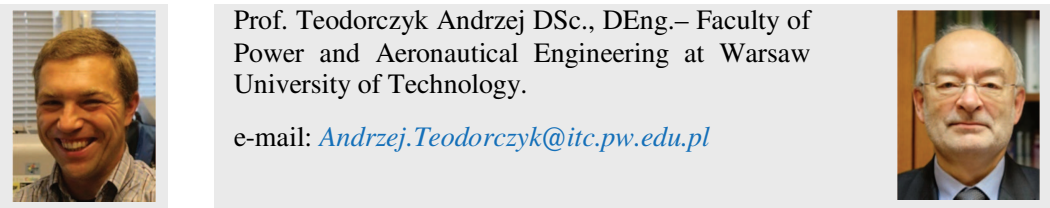